\title{
Adopción del modelo de contabilidad simplificada en una microempresa colombiana por primera vez $y$ sus posibles efectos ${ }^{1}$
}

Recibido: 17 de mayo de 2013

Aprobado: 15 de octubre de 2013

\author{
Daniel Darío Daza Delgado² \\ David Esteban Altamar Romero ${ }^{3}$
}

\begin{abstract}
Daza, D. D., \& Altamar, D. E. (2013). Adopción del modelo de contabilidad simplificada en una microempresa colombiana por primera vez y sus posibles efectos. Activos 21, 191-231.
\end{abstract}

Clasificación JEL: xxxxx

\section{Resumen}

Con la entrada en vigencia de las Normas Internacionales de Información Financiera (NIIF) se hace necesario analizar el entorno contable actual de las empresas colombianas, y en especial, las dinámicas que han emprendido frente al proceso de convergencia a las NIIF. El presente trabajo busca identificar las diferentes características de las microempresas colombianas, los sectores en que operan y las actividades que realizan, con el fin de caracterizar la observancia de las normas legales en materia de contabilidad

1 El presente trabajo es una versión derivada del trabajo de grado que lleva el mismo nombre, y que fue presentado para la obtención del título de contadores públicos de la Universidad Santo Tomás.

2 Contador Público. Universidad Santo Tomas. Correo electrónico: daniel_daza_d@ hotmail.com

3 Contador Público. Universidad Santo Tomas. Correo electrónico: davidesteban altamar@hotmail.com 
y la situación de estas entidades frente a la implementación de sistemas de contabilidad simplificada.

Con este fin el documento desarrolla un caso práctico donde se explica la metodología de ajustes y traslados entre cuentas, así como el cambio en la presentación y posibles alteraciones que llegarían a ser relevantes dentro de la situación financiera de la microempresa en el proceso de convergencia a modelos de contabilidad simplificada en el entorno de las NIIF.

\title{
Palabras clave
}

Microempresas, contabilidad simplificada, convergencia, Normas Internacionales de Información Financiera.

Daza, D. D., \& Altamar, D. E. (2013). Adoption by the first time of simplify accounting model in a colombian micro-enterprise, and their posible effects. Activos 21, 191-231.

\begin{abstract}
With the coming into force of the International Financial Reporting Standards (IFRS) it is necessary to analyze the current accounting environment of Colombian companies, and especially, the dynamic they have undertaken regarding the convergence process to the IFRS. This paper seeks to identify the different characteristics of the Colombian very small businesses, the sectors in which they operate and the activities they perform, in order to characterize the observance of legal rules in accounting matters and the situation of these entities regarding the implementation of simplified accounting systems.

With this purpose the document develops a practical case where it explains the methodology of adjustments and transfers between accounts, as well as the change in the presentation and possible alterations that may be relevant in the financial situation of the very small business in
\end{abstract}


the convergence process to models of simplified accounting in the IFRS environment.

\section{Keywords}

Very small businesses, simplified accounting, convergence, International Financial Reporting Standards.

\section{Daza, D. D., \& Altamar, D. E. (2013). Adaptation du modèle de comptabilité simplifiée dans une micro-entreprise colombienne une première fois et ces effets posibles. Activos 21, 191-231.}

\section{Résumé}

Suite à l'entrée en vigueur des Normes Internationales d'Information Financière (NIIF), il est nécessaire d'analyser le domaine comptable actuel des entreprises colombiennes et spécialement, les dynamiques entreprises face au procès de convergence aux NIIF. La présente étude vise à identifier les différentes caractéristiques des micro-entreprises colombiennes, le secteur dans lequel elles opèrent et les activités réalisées, afin d’analyser l'observation des normes légales en matière comptable et la situation de ces entités, face à la mise en œuvre de systèmes de comptabilité simplifiée.

A cette fin, le document développe un exemple pratique où la méthodologie d'ajustements et transferts entre comptes est expliquée, ainsi que les changements dans la présentation et possibles altérations, qui pourraient être significatifs dans la situation financière de la micro-entreprise, dans le processus de convergence vers des modèles de comptabilité simplifiée dans le domaine des NIIF.

\section{Mots clés:}

Micro-entreprise, comptabilité simplifiée, convergence, Normes Internationales d'Information Financière. 


\section{Introducción}

El informe realizado en el año 2007 por la Corporación para el Desarrollo de las microempresas - Observatorio Colombiano de las Microempresa (OMC) señala que las microempresas en Colombia representan la fuerza económica con mayor participación en la totalidad del conglomerado empresarial del país (Giraldo, Estadistica de la Microempresa en Colombia, Analisis Comparativo 1990-2005, 2007). Por dicha razón, se vuelve fundamental que estas organizaciones cuenten con una gran cantidad y calidad de las herramientas contables que les permitan enfrentar de mejor manera el proceso de internacionalización en el cual se ven inmersas y especialmente que dichas transiciones no impliquen mayores inconvenientes sobre la interpretación y utilización de la norma contable internacional.

Las NIIF proponen que el sistema de información contable sea una herramienta fundamental para la toma de decisiones dentro de las organizaciones. Esto implica que además de asegurarse de que la información sea veraz y clara para todos los usuarios de la información, sea pertinente y corresponda a las demandas propias de los entornos organizacionales. Sin embargo, por cuestiones de cultura del entorno colombiano la contabilidad se percibe más como una exigencia de la administración tributaria, dejando de lado su utilidad para apoyar las decisiones gerenciales y administrativas.

El presente documento busca brindar cierto nivel de orientación a las microempresas colombianas en el proceso de cambio de normatividad contable hacia modelos de contabilidad simplificada, con el fin de que la transición se haga recurriendo al uso de herramientas al alcance de los propietarios y contadores de las microempresas, que faciliten el desarrollo de los aspectos esenciales de las organizaciones (contable, financiero, gerencial y tributario). Adicional a ello el texto señala las ventajas de la presentación de la información contable de las microempresas bajo el modelo NIIF y los principales factores que se deben tener en cuenta para poder implementarlas correctamente. 


\section{Definición y clasificación de las empresas en Colombia}

En primer lugar se hace necesario definir el término empresa, según la comisión Europea una empresa es "una entidad que ejerce una actividad económica, independientemente de su forma jurídica" (Comision Europea, 2006). La norma colombiana, y particularmente el Código de Comercio, señala: "Se entenderá por empresa toda actividad económica organizada para la producción, transformación, circulación, administración o custodia de bienes, o para la prestación de servicios. Dicha actividad se realizará a través de uno o más establecimientos de comercio". (Código Comercio, 1971).

Pero como es sabido, existen un conjunto de empresas que por diferentes factores (número de trabajadores, infraestructura de operaciones que poseen, inversión inicial y alcances del mercado competitivo) clasifican en la denominación de microempresa, esta definición no es universal y por ello hay que identificar las diferentes definiciones en distintos espacios normativos.

El artículo $2^{\circ}$ de la Ley 590 de 2000 define microempresa como "toda unidad económica ya sea fami-empresa, pequeñas y medianas, que realiza actividades de explotación económica mediante persona natural o jurídica, en la realización de actividades industriales, comerciales, agropecuarias y de servicios".

Adicionalmente, la norma también señala que una microempresa debe cumplir con una serie de parámetros:

- Planta de personal no superior a diez empleados.

- Activos totales, excluida la vivienda, por valor inferior a quinientos (500) salarios mínimos mensuales legales vigentes.

La Ley 1450 de 2011 en su artículo 43, modifica el citado artículo 2 de la Ley 590 de 2000, y aclara: 
Para todos los efectos, se entiende por empresa, toda unidad de explotación económica, realizada por persona natural o jurídica, en actividades agropecuarias, industriales, comerciales o de servicios, en el área rural o urbana. Para la clasificación por tamaño empresarial, entiéndase micro, pequeña, mediana y gran empresa, se podrá utilizar uno o varios de los siguientes criterios:

1. Número de trabajadores totales.

2. Valor de ventas brutas anuales.

3. Valor activos totales.

Para efectos de los beneficios otorgados por el Gobierno nacional a las micro, pequeñas y medianas empresas el criterio determinante será el valor de ventas brutas anuales.

En este sentido, la Ley 590 de 2000 en su artículo 8 determina que:

Las medianas empresas son aquellas que poseen entre cincuenta (51) y doscientos (200) trabajadores a su cargo, a su vez que sus activos totales estén entre 5.001 a 30.000 salarios mínimos mensuales legales vigentes.

Las pequeñas empresas son las que se poseen personal entre once (11) y cincuenta (50) trabajadores y unos activos totales con una cuantía entre 501 y 5.000 salarios mínimos mensuales legales vigentes.

Las microempresas son las entidades que poseen como máximo diez (10) trabajadores y sus activos totales son inferiores a 500 salarios mínimos legales vigente. 


\section{Relevancia de las microempresas en la economía colombiana}

La economía de las microempresas es sumamente importante para Colombia. En la figura 1 se indica el peso específico que tienen estas organizaciones en el total de las organizaciones empresariales del país, el Observatorio Colombiano de las Microempresas (Giraldo, Estadistica de la Microempresa en Colombia, Analisis Comparativo 1990-2005, 2007) señala que de un total de 1.393 .712 empresas, las micro representan el $96 \%$, es decir, un total de 1.338.220 unidades empresariales, le siguen las pequeñas y medianas empresas con un 3,84\% (53.647) y las grandes empresas con el $0,13 \%$ (1.845) (ver figura 2).

Figura 1. Tipos de empresas en Colombia

\section{Adopción por primera vez del modelo de contabilidad simplificada en una microempresa colombiana y sus posibles efectos}

Figura 1. Tipos de empresas en Colombia

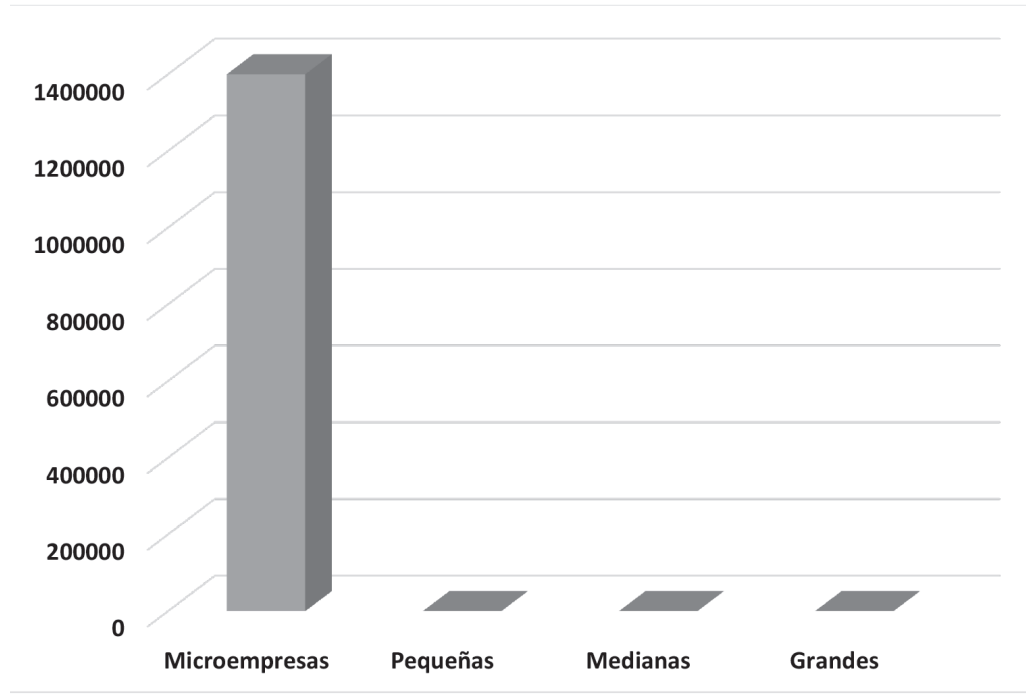

Fuente: Tomado de Giraldo (2007). 
Figura 2. Distribución porcentual de empresas en Colombia

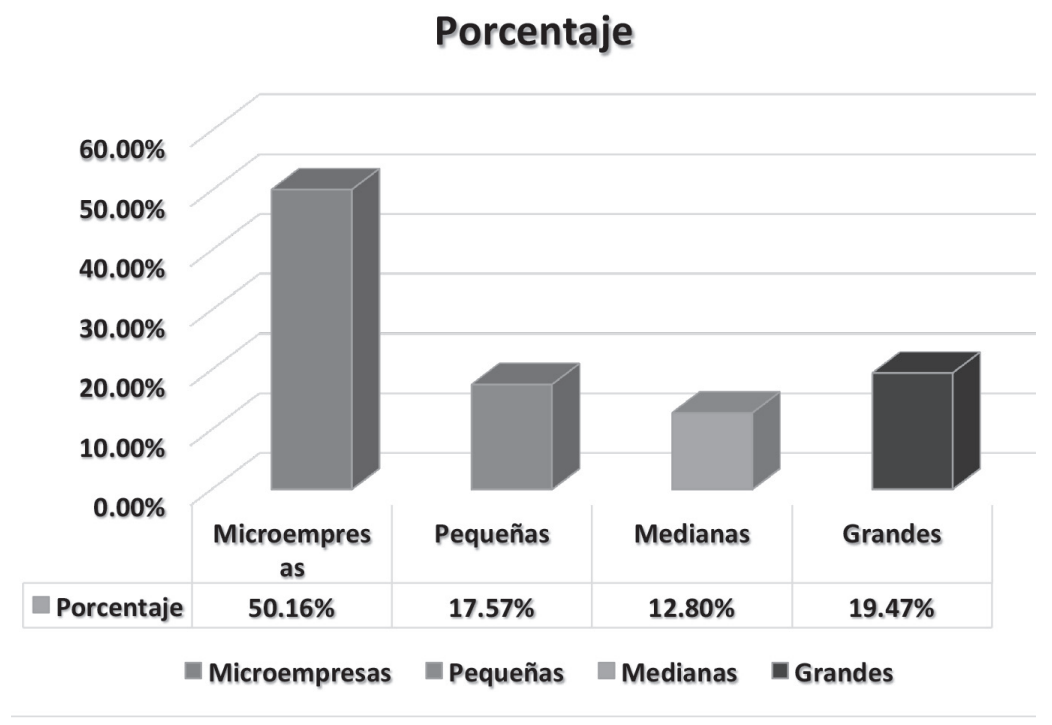

Fuente: Tomado de Giraldo (2007).

En este mismo sentido hay que señalar que las microempresas, según cifras del Departamento Administrativo Nacional de Estadística (DANE, 2005) agrupan el 50,16 \% de la fuerza laboral del país, ubicados en mayor parte por las microempresas unipersonales, y en menor cuantía por microempresas con un personal de entre dos y cinco empleados.

El Observatorio Colombiano de la Microempresa (Giraldo, Estadistica de la Microempresa en Colombia, Analisis Comparativo 1990-2005, 2007), indica que en términos sectoriales la mayor concentración de microempresas se encuentra en el sector comercio (54,6\%), seguido por Servicios $(31,60 \%)$ y finalmente la industria (12,22 \%) (ver figura 3$)$. 
Figura 3. Composición sectorial

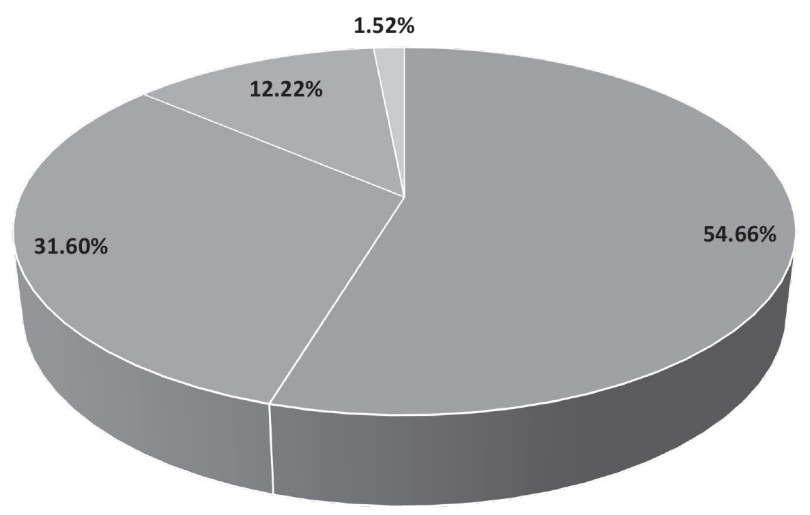

Fuente: Tomado de Giraldo (2007).

Para ser precisos hay que indicar que la actividad que más desarrollan las microempresas es el comercio al por menor en establecimientos no especializados, con surtido compuesto principalmente de alimentos (víveres en general), bebidas y alcohol, con el 12,84 \%, lo que en la práctica corresponde a negocios como tiendas de barrio y misceláneas (ver tabla 1).

Figura 4. Tamaño de las microempresas

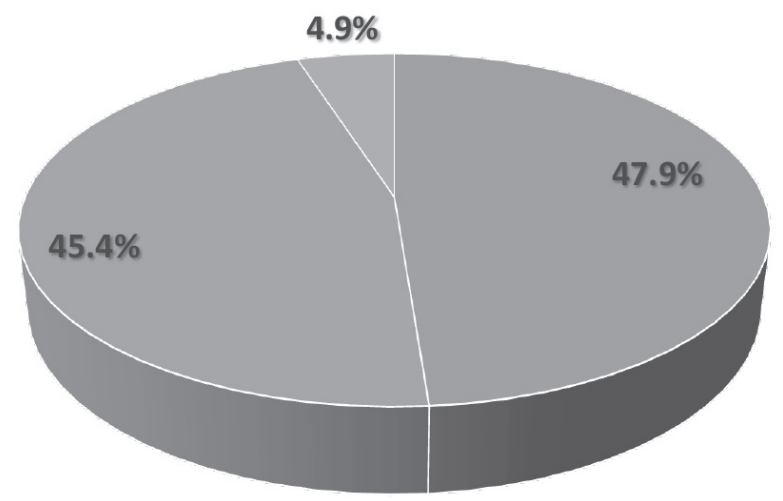

Fuente: Tomado de Giraldo (2007). 
Tabla 1. Actividades económicas de las microempresas

\begin{tabular}{|c|c|c|}
\hline CIIU & ACTIVIDADES & $\%$ \\
\hline 5211 & Ventas al por menor de alimentos, bebidas y tabaco & 12,84 \\
\hline 5219 & $\begin{array}{l}\text { Ventas al por menor de artículos diferentes de alimentos, bebidas } \\
\text { y tabaco }\end{array}$ & 6,14 \\
\hline 5233 & Compra-venta ropa en general y sus accesorios & 3,75 \\
\hline 5221 & Compra-venta frutas y verduras, productos agrícolas & 3,18 \\
\hline 5521 & Restaurantes servicio a la mesa & 3,15 \\
\hline 5020 & Mantenimiento-reparación vehículos automotores & 2,96 \\
\hline 5529 & Otros expendios de comida & 2,90 \\
\hline 5522 & Café-frutería Servicio a la mesa & 2,75 \\
\hline 5225 & Compra-venta Cigarrerías, bebidas, tabaco & 2,75 \\
\hline 6421 & Correo-Telec-Servicios telefónicos, celulares & 2,60 \\
\hline 9302 & $\begin{array}{l}\text { Otros servicios Salones de belleza, peluquerías, tratamientos de } \\
\text { belleza }\end{array}$ & 2,52 \\
\hline 3699 & Otras industrias manufactureras & 2,48 \\
\hline 5530 & Expendio de bebidas alcohólicas & 2,38 \\
\hline 5223 & Compra-venta Carnes & 1,72 \\
\hline 5272 & Mantenimiento-reparación Enseres Domésticos & 1,64 \\
\hline 5224 & Compra-venta Confitería, dulces & 1,49 \\
\hline 5231 & Compra-venta Drogas, cosméticos, perfumes & 1,48 \\
\hline 1810 & Ropa en general, confecciones, acoplamiento de piezas, gorros & 1,46 \\
\hline 5241 & Compra-venta Ferreterías, cerrajerías, vidrio, marqueterías & 1,43 \\
\hline 5229 & Compra-venta Otros alimentos & 1,26 \\
\hline 5234 & Compra-venta Calzado, artículos de cuero, bolsos & 1,21 \\
\hline 5249 & Compra-venta Otros productos de consumo & 1,17 \\
\hline 5271 & Mantenimiento-reparación Efectos personales & 1,10 \\
\hline
\end{tabular}




\begin{tabular}{llc}
\hline CIIU & \multicolumn{1}{c}{ ACTIVIDADES } & $\%$ \\
\hline 5040 & Compra-venta Motos y sus partes, piezas y accesorios & 1,00 \\
\hline 5244 & Compra-venta Papelerías, librerías, útiles escolares & 0,97 \\
\hline 5222 & Compra-venta Productos lácteos, leche, huevos & 0,94 \\
\hline 8512 & Salud, Servicios Sociales-Centros de salud, consultorios médicos & 0,89 \\
\hline 8011 & Educación-preescolar & 0,79 \\
\hline 1551 & Productos de panadería, pan, bizcochos, buñuelos, tamales & 0,76 \\
\hline 5237 & Compra-venta Productos para el hogar & 0,73 \\
\hline
\end{tabular}

Fuente: Tomado de Giraldo 2007.

\section{Desarrollo y situación actual de la microempresa en Colombia}

Las microempresas surgen y se desarrollan como un medio de independencia laboral y una respuesta a la carencia de fuentes formales de empleo. En los últimos años han tenido un auge en el panorama económico del país, impulsadas por la difusión de capacitaciones sobre emprendimientos empresariales y la ampliación de líneas y canales especializados en créditos de fomento para las microempresas, bajo la premisa de que constituyen una herramienta para impulsar el crecimiento económico y combatir la pobreza.

Los esfuerzos del gobierno por la promoción y organización de este tipo de empresas han sido importantes, sin embargo, el carácter irregular y de informalidad que poseen las microempresas ha hecho difícil esta labor, los altos grados de informalidad han hecho imposible separar de las microempresas este carácter de informalidad, esto ocurre en la medida en que el contexto social en el cual son creadas es precario y donde la mayor parte de las microempresas son en realidad esfuerzos para lograr un ingreso que permita la subsistencia, más que una opción de creación de valor económico. 
En este sentido, hay que señalar que la Encuesta sobre Servicios Financieros Informales realizada por Asociación Nacional de Instituciones Financieras (ANIF, 2007) indica que la totalidad de las microempresas se ubican en sectores de estratos socioeconómicos uno (13,43\%), dos (43,73 $\%)$ y tres $(42,84 \%)$, de estas, el $21 \%$ no presenta ningún carácter de formalidad, además en cuanto más bajo es el estrato socioeconómico menor es la cantidad de empresas inscritas en Cámara de Comercio.

Esto se debe a que representan una mayor facilidad para las empresas, hacer parte del sector informal, así pueden evitar impuestos y regulaciones, que según indican, resultan ser mayores obstáculos para este tipo de empresas que para las de mayor tamaño. (Montoya, 2011, p. 29).

En las décadas de los años ochenta y noventa, el gobierno a través del Consejo Nacional de Política Económica y Social (CONPES), formuló planes para el desarrollo microempresarial que buscaban su mejoramiento, fortalecimiento y posicionamiento, mediante la amplificación de la cobertura y la calidad de los programas de apoyo y financiamiento de carácter público y privado. El ingreso del sector financiero a las políticas de fortalecimiento y fomento la creación de microempresas se hizo a través de la modalidad de micro créditos, los cuales marcan un precedente que ha contribuido en la constante creación de este tipo de empresas, aunque no tanto a su supervivencia y expansión.

Pese al incremento del apoyo del sector financiero, datos del DANE (2013) indican que la principal fuente de financiación para la creación de microempresas son los ahorros personales seguido por los préstamos bancarios y los prestamos familiares (ver figura 5).

En este contexto, el gobierno nacional junto con el Congreso de la República, aprobaron y sancionaron la Ley 905 (2004), la cual busca "estimular la promoción y formación de mercados altamente competitivos mediante el fomento de la permanente creación y funcionamiento de la mayor cantidad de MyPimes". 
Figura 5. Fuentes de financiamiento para la creación de microempresas

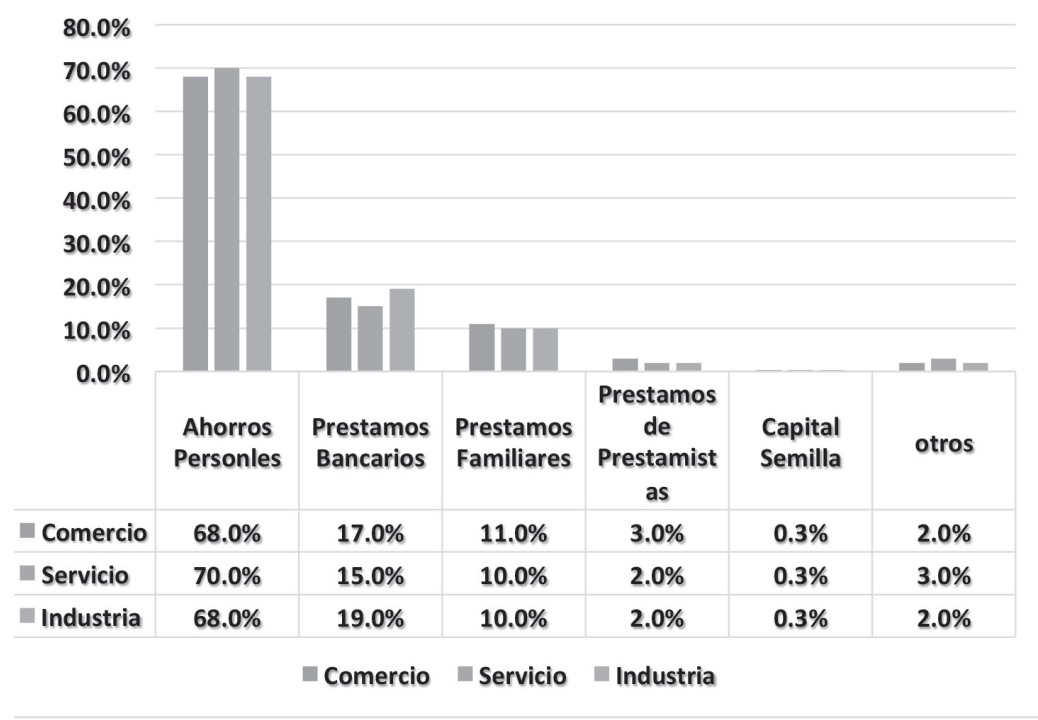

Fuente: Departamento Administrativo Nacional de Estadística (DANE, 2013).

El documento CONPES 3484 (Departamento Nacional de Planeacion, 2007), señala las dificultades que tienen las microempresas para satisfacer la documentación, requisitos y garantías que el mercado financiero impone, las cuales no logran ser cumplidas por los propietarios, y es por ello que se ven obligados a recurrir a otro medios de financiación.

Pese a estos esfuerzos que incluyen no solo el fomento a través de créditos, el otorgamiento de beneficios tributarios, las facilidades para la creación de Microempresas, el impulso a organizaciones creadas para apoyar la creación y sostenimiento de las microempresas (por ejemplo la Asociación Colombiana de las Micro, Pequeñas y Medianas Empresa (ACOPI) y el Fondo Nacional para el Desarrollo de la Micro, Pequeña y Mediana Empresa (FONAPY)) las cifras de los censos y encuestas realizadas muestran que el carácter de informalidad e irregularidad sigue siendo muy 
alto, por ello, no es de extrañar que el 47,9\% del total de microempresas son de carácter unipersonal, en la mayor parte de los casos sus propietarios son personas que cuentan con escasos recursos, lo cual impide la utilización de herramientas de legalidad, control y transparencia, que implican un costo de funcionamiento muy alto. El Ministerio de Industria, Comercio y Turismo (2013) indica al respecto que aproximadamente el $59 \%$ de los establecimientos de comercio no poseen registro mercantil y el $55 \%$ no poseen registros formales sobre su actividad económica.

Ahora bien, en lo que respecta al uso de la contabilidad en esta tipo de organizaciones, el DANE (2013) caracterizó el uso de diferentes sistemas de control e información contable en las microempresas. Los resultados se pueden observar en la figura 6.

Figura 6. Tipos de registro contable usados en microempresas

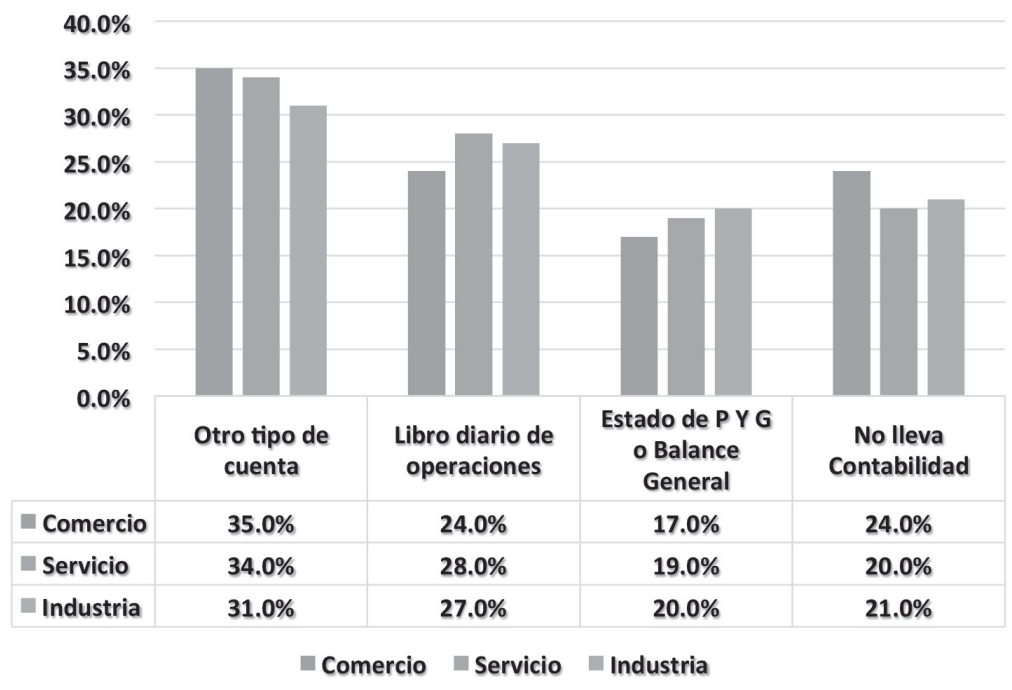

Fuente: Tomado de Departamento Administrativo Nacional de Estadística (DANE, 2012). 
Esta información sugiere la existencia de dos grandes problemas que pueden complicar el proceso de convergencia de los sistemas de contabilidad de las microempresas hacia Estándares Internacionales de Contabilidad Simplificada para Microempresas.

El primero de ellos consiste en la falta de homogeneidad en el registro de sus operaciones contables, esto ocurre principalmente porque cada empresa se enfoca hacia las necesidades individuales que posea el negocio. El primer paso para superar este problema es el de buscar la unificación de la información con que actualmente se cuenta para que de esta forma cumpla con el objetivo principal de los estándares internacionales, el de conseguir homogeneidad y comparabilidad entre todas y cada una de las empresas sin importar el tamaño, tipo de negocio, o sector al que pertenezca la información que se genera.

El segundo problema es el de aquellas empresas que no poseen ningún tipo de contabilidad (casi una cuarta parte del total de microempresas), esto ratifica el carácter irregular que poseen estas organizaciones, lo cual hace necesario resaltar que el principal cometido en la creación de microempresas es desarrollar un medio de subsistencia, de allí que los recursos obtenidos en el desarrollo de la actividad económica son destinados a necesidades básicas, la compra de alimentos, el pago de vivienda, salud y educación. El pequeño margen de ganancia que dejan estos negocios hace muy difícil que esta se destine a la implementación de un sistema de contabilidad, al pago de asesorías o a la implementación de estándares de contabilidad simplificada para sus negocios.

\section{Identificación de grupos de empresas para la adopción contable bajo las NIIF}

La Ley 1314 de 2009 llevó a Colombia a un proceso de convergencia de sus sistemas de contabilidad hacia estándares internacionales, y particularmente hacia el referente de las NIIF. De igual manera, indicó las autoridades competentes para la vigilancia y cumplimiento de la calidad y consistencia 
de dicha información (Consejo Técnico de la Contaduría Pública (CTCP) fundamentalmente), y a esta legislación se la ha complementado con un amplio marco regulador en este sentido, la Superintendencia de Sociedades expidió la circular externa número 115-000002 del 14 de marzo de 2012, donde detalla el proceso para la convergencia a NIIF y adicionalmente, el CTCP hizo público el documento de direccionamiento estratégico en el cual se presenta la hoja de ruta para dicha convergencia.

Un aspecto interesante del documento de direccionamiento estratégico es que clasificó a las empresas en tres grupos diferentes, los cuales deben hacer procesos diferenciados de convergencia. La tabla 2 muestra los grupos definidos.

Tabla 2. Grupos de Empresas de acuerdo al proceso de convergencia a NIIF

\begin{tabular}{l} 
a. Emisores de valores, \\
b. Entidades de interés público, y \\
c. Empresas de tamaño grande clasificadas como tales según la \\
Ley 590 de 2000 modificatoria por la Ley 905 de 2004 y normas \\
posteriores que la modifique o sustituyan que no sean emisores \\
de valores ni entidades de interés público y que cumplan con los \\
siguientes requisitos adicionales: \\
$\begin{array}{l}\text { 1. Ser subordinada o sucursal de una compañía extranjera que } \\
\text { aplique NIIF. }\end{array}$ \\
$\begin{array}{l}\text { 2. Ser subordinada o matriz de una compañía nacional que deba } \\
\text { aplicar NIIF. }\end{array}$ \\
$\begin{array}{l}\text { 3. Realizar importaciones o exportaciones que representen más } \\
\text { del } 50 \% \text { de las compras o de las ventas, respectivamente, del } \\
\text { año gravable inmediatamente anterior al ejercicio sobre el que se } \\
\text { informa. }\end{array}$ \\
$\begin{array}{l}\text { 4. Ser matriz, asociada o negocio conjunto de una o más entidades } \\
\text { extranjeras que apliquen NIIF plenas. }\end{array}$ \\
\hline
\end{tabular}




\begin{tabular}{ll}
\hline a. Empresas de tamaño grande clasificadas como tales según la Ley \\
590 de 2000 modificada por la Ley 905 de 2004 y normas posteriores \\
que la modifiquen o sustituyan y que no cumplan con los requisitos \\
del literal (c) del grupo 1, \\
b. Empresas de tamaño mediano y pequeño clasificadas como \\
tales según la Ley 590 de 2000 modificada por la Ley 905 de 2004 \\
yRUPO normas posteriores que la modifiquen o sustituyan y que no sean \\
emisores de valores ni entidades de interés público, y \\
c. Microempresas clasificadas como tales según la Ley 590 de 2000 \\
modificada por la Ley 905 de 2004 y normas posteriores que la \\
modifiquen o sustituyan y cuyos ingresos anuales sean iguales o \\
superiores a 15.000 SMLMV. \\
a. Personas naturales o jurídicas que cumplan los criterios \\
establecidos en el Art. 499 del ET y normas posteriores que la \\
modifiquen, para el efecto, se tomará el equivalente a UVT, en \\
salarios mínimos legales vigentes, \\
b. Microempresas clasificadas como tales según la Ley 590 de 2000 \\
modificada por la Ley 905 de 2004 y normas posteriores que la \\
modifiquen o sustituyan que no cumplan con los requisitos para ser \\
incluidas en el grupo 2 ni en el literal anterior.
\end{tabular}

Fuente: Tomado de Superintendencia de Sociedades (2013).

Para el grupo 3, que es el que interesa en este documento, los estándares implementados se denominan genéricamente contabilidad simplificada y los requisitos de la misma están compilados en el Decreto 2706 de 2012. A pesar de la simplicidad de esta información, el cronograma de implementación es el mismo que para las empresas del grupo 1. Para las Pymes que hacen parte del grupo 2 (menos del 1,2 \% del total de Pymes) el direccionamiento estratégico señala que aplicaran las NIIF para Pymes, que es un modelo más ligero en términos de requerimientos de información respecto a NIIF plenas, la aplicabilidad para las empresas del grupo 2 está proyectada para iniciarse un año más tarde (Decreto 2706, 2012). A pesar de que la etapa de planeación contenida en el direccionamiento estratégico del CTCP ya se ejecutó, los periodos de transición y obligatoriedad se han venido aplazando y prolongando debido a factores diversos, especialmente 
por el poco grado de formación y comprensión por parte de contadores y empresarios sobre el proceso de convergencia y por las trabas institucionales que surgen en diversos sectores.

Hay que anotar, que la Ley 1314 de 2009, señala claramente las normas que deberán ser utilizadas para las empresas de los grupos 1 y 2, sin embargo, la regulación contable internacional no contempla un marco para microempresas del tamaño y dinámica que tienen las nuestras, pues el modelo de NIIF para Pymes es realmente aplicable a lo que aquí llamamos medianas y grandes empresas (excluyendo a las que cotizan en bolsa) esto obliga a que el CTCP deba implementar un marco normativo especial para microempresas que en principio a partir de lo planteado por los elementos definidos en el proyecto ISAR (International Standards of Accounting and Reporting) desarrollado por la Conferencia de las Naciones Unidas Sobre Comercio y Desarrollo (UNCTAD, por sus siglas en inglés), con este referente, se produjo el Decreto 2706 de 2012 "Por el cual se reglamenta la Ley 1314 de 2009 sobre el marco técnico normativo de información financiera para las microempresas" el cual brinda las pautas de registro y control, las obligaciones de información y de responsabilidad social para las empresas del grupo 3.

\section{El modelo de contabilidad simplificada para microempresas}

En términos de las NIIF solo están descritas dos clases de empresas: las empresas que cotizan en bolsa o empresas de "interés público", las cuales equivalen a las definidas para el grupo 1; y las empresas que no cotizan en bolsa las cuáles están relacionadas con las definidas en el grupo 2. Las primeras deben aplicar los estándares NIIF plenos con todos los requerimientos de información que estos conllevan, mientras que las empresas del grupo 2 deben aplicar el modelo NIIF Pymes el cual tiene unas normas menos exigentes en materia de revelación y registro de información. 
En el caso de las empresas del grupo 3, el Consejo Técnico de la Contaduría emitió el 28 de septiembre de 2012 el documento Norma de Información Financiera para las Microempresas, el cual sentó las bases para la creación de la norma definitiva que servirá como guía y direccionamiento contable para las microempresas, y demás entidades catalogadas del grupo 3.

El Decreto 2706 del 2012 emitido con posterioridad, surge como respuesta a la falta de un marco normativo contable y financiero de fácil entendimiento para las microempresas, a la vez, como norma única y general. Para su construcción fueron tomados en cuenta los aspectos esenciales de la Ley 1314 de 2009, los planteamientos básicos del modelo NIIF y los principios establecidos en el modelo ISAR.

Este decreto tiene como objetivo "establecer un régimen simplificado de contabilidad de causación, para todas las microempresas" (Decreto 2706, 2012), adicionalmente, la norma establece su cumplimiento para las empresas formales, así como para las informales que estén en proceso de formalización, brindándoles un marco normativo de contabilidad básico para la generación de reportes con información útil y veraz para los grupos de interés (Estado, clientes, proveedores, etc.). Aunque se trate de un marco normativo desarrollado a partir de NIIF para Pymes, las normas de contabilidad simplificada no presentan muchas de las disposiciones establecidas en NIIF plenas y NIIF para Pymes, no obstante el hecho de tratarse de un marco normativo más compacto y simple no es causante de que la información y los reportes que se generen no sean comparables con los creados a partir del marco NIIF.

El Decreto 2706 de 2012 establece unas fechas y plazos para su puesta en marcha, la tabla 3 señala el cronograma para la implementación de normas simplificadas. 


\section{Ejemplo de adopción en una microempresa colombiana del sector comercial del modelo de contabilidad simplificada por primera vez}

El proceso de transición que las microempresas deben asumir en sus modelos contables implica al menos la revisión de los siguientes criterios:

- Todos los activos y pasivos deben ser tratados según la nueva normativa aplicable.

- No reconocer activos o pasivos que la nueva norma no permita.

- Realizar la reclasificación de las partidas de activo, pasivo y patrimonio, que se hayan realizado según la normatividad anterior y que según la norma actual pertenezcan a otro grupo.

- Aplicar la nueva normativa en la medición y reconocimiento de activos y pasivos.

Tabla 3. Cronograma de aplicación del proceso de convergencia entidades del grupo 3

\begin{tabular}{|c|c|c|c|c|}
\hline \multirow{2}{*}{ Paso } & \multirow{2}{*}{ Título } & \multicolumn{2}{|c|}{ Fechas } & \multirow{2}{*}{ Descripción } \\
\hline & & De & $\mathbf{A}$ & \\
\hline 1 & $\begin{array}{l}\text { Período de } \\
\text { preparación } \\
\text { obligatoria }\end{array}$ & $\begin{array}{l}1 \text { de enero } \\
\text { de } 2013\end{array}$ & $\begin{array}{l}31 \text { de } \\
\text { diciembre } \\
\text { de } 2013\end{array}$ & $\begin{array}{l}\text { Tiempo durante el cual la } \\
\text { microempresa realizó actividades } \\
\text { relacionadas con el proyecto de } \\
\text { convergencia. }\end{array}$ \\
\hline 2 & $\begin{array}{l}\text { Fecha de } \\
\text { transición }\end{array}$ & $\begin{array}{l}1 \text { de enero } \\
\text { de } 2014\end{array}$ & N/A & $\begin{array}{l}\text { Momento en el cual inició la } \\
\text { construcción de primer año de } \\
\text { información financiera de acuerdo } \\
\text { con los nuevos estándares. }\end{array}$ \\
\hline 3 & $\begin{array}{l}\text { Estado de } \\
\text { la situación } \\
\text { financiera de } \\
\text { apertura }\end{array}$ & $\begin{array}{l}1 \text { de enero } \\
\text { de } 2014\end{array}$ & N/A & $\begin{array}{l}\text { Primera medición de los activos, } \\
\text { pasivos y patrimonio mediante } \\
\text { normas internacionales. }\end{array}$ \\
\hline
\end{tabular}




\begin{tabular}{|c|c|c|c|c|}
\hline \multirow{2}{*}{ Paso } & \multirow{2}{*}{ Título } & \multicolumn{2}{|c|}{ Fechas } & \multirow{2}{*}{ Descripción } \\
\hline & & $\mathrm{De}$ & $\mathbf{A}$ & \\
\hline 4 & $\begin{array}{l}\text { Período de } \\
\text { transición }\end{array}$ & $\begin{array}{l}1 \text { de enero } \\
\text { de } 2014\end{array}$ & $\begin{array}{l}31 \text { de } \\
\text { enero de } \\
2014\end{array}$ & $\begin{array}{l}\text { En este periodo se deberá llevar la } \\
\text { contabilidad de la microempresa } \\
\text { bajo normatividad local (Decreto } \\
2649 \text { y } 2650 \text { de 1993) para } \\
\text { efectos legales y tributarios, } \\
\text { pero en paralelo se deberá llevar } \\
\text { la contabilidad bajo norma } \\
\text { internacional. }\end{array}$ \\
\hline 5 & $\begin{array}{l}\text { Últimos estados } \\
\text { financieros con } \\
\text { norma local }\end{array}$ & $\begin{array}{l}1 \text { de enero } \\
\text { de } 2014\end{array}$ & $\begin{array}{l}31 \text { de } \\
\text { enero de } \\
2014\end{array}$ & $\begin{array}{l}\text { Se refiere a los estados financieros } \\
\text { preparados al } 31 \text { diciembre de } \\
2014 \text { bajo norma local. }\end{array}$ \\
\hline 6 & $\begin{array}{l}\text { Fecha de } \\
\text { aplicación }\end{array}$ & $\begin{array}{l}1 \text { de enero } \\
\text { de } 2015\end{array}$ & $\mathrm{~N} / \mathrm{A}$ & $\begin{array}{l}\text { A partir de esta fecha se están a } \\
\text { la utilización de norma local y } \\
\text { comenzará la aplicación de los } \\
\text { nuevos estándares de información } \\
\text { financiera. }\end{array}$ \\
\hline 7 & $\begin{array}{l}\text { Primer período } \\
\text { de aplicación }\end{array}$ & $\begin{array}{l}1 \text { de enero } \\
\text { de } 2015\end{array}$ & $\begin{array}{l}31 \text { de } \\
\text { diciembre } \\
\text { de } 2015\end{array}$ & $\begin{array}{l}\text { Período en el cual la contabilidad } \\
\text { se llevará para todos los medios la } \\
\text { contabilidad simplificada. }\end{array}$ \\
\hline 8 & Fecha de aporte & $\begin{array}{l}1 \text { de enero } \\
\text { de } 2015\end{array}$ & N/A & $\begin{array}{l}\text { Fecha de presentación de los } \\
\text { primeros estados financieros } \\
\text { comparativos de acuerdo con los } \\
\text { nuevos estándares. }\end{array}$ \\
\hline
\end{tabular}

Fuente: Elaborado con datos del Decreto 2706 (2012).

A continuación, se presenta el conjunto de reclasificaciones y ajustes que deberán llevarse a cabo sobre los Estados Financieros realizados bajo los lineamientos del Decreto 2649 de 1993, y se identificaran las principales diferencias en cuanto a presentación, complejidad de la convergencia de la información y las conclusiones finales en cuanto a los dos estados financieros principales y sus notas. Este ejercicio se construye a partir de unos esquemas propios de una microempresa del sector de comercio e inicialmente señala la estructura actual de balance bajo las normas del decreto 2649 y luego las reclasificaciones elementales que deben ser acometidas en el marco NIIF de contabilidad simplificada. 


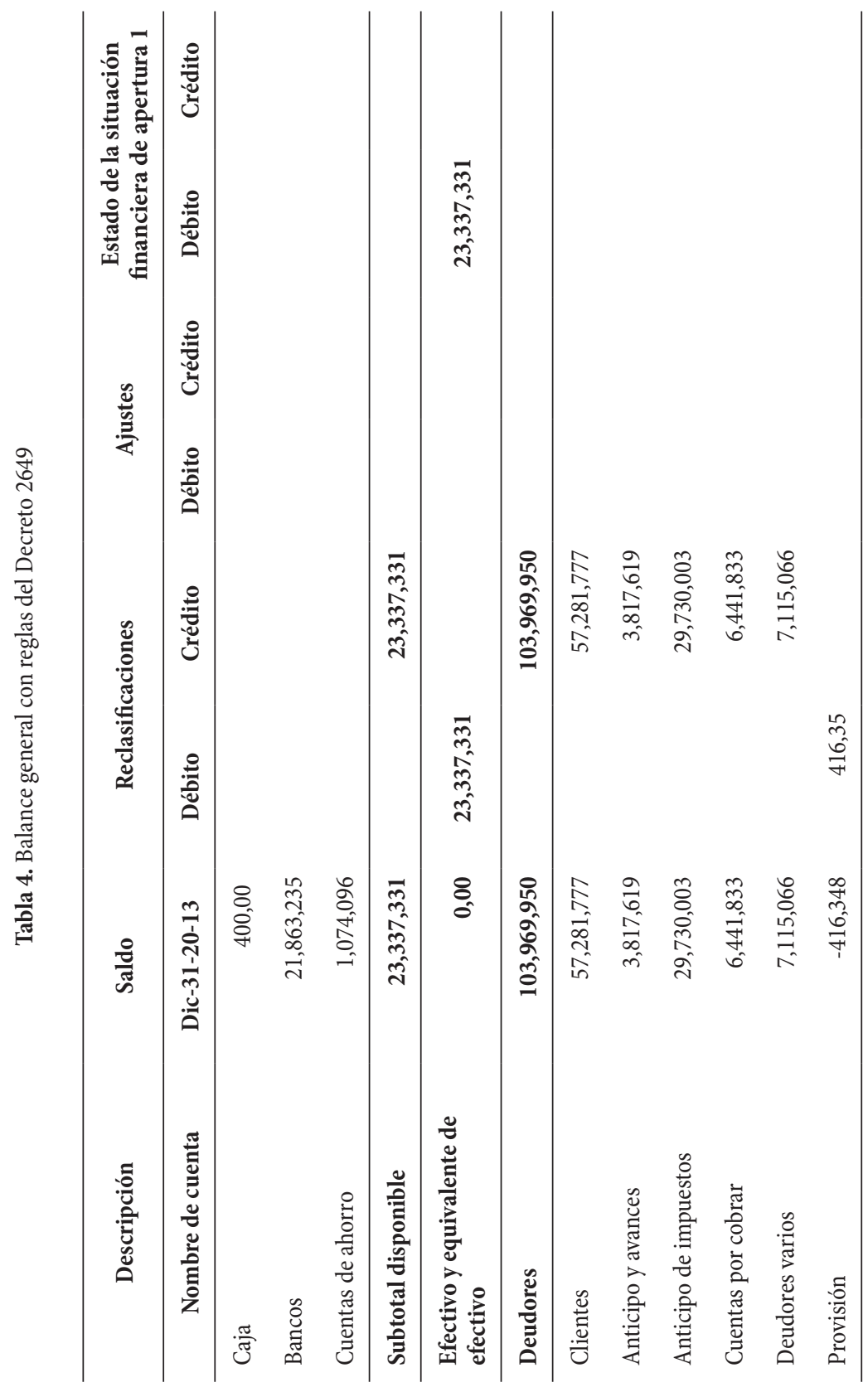




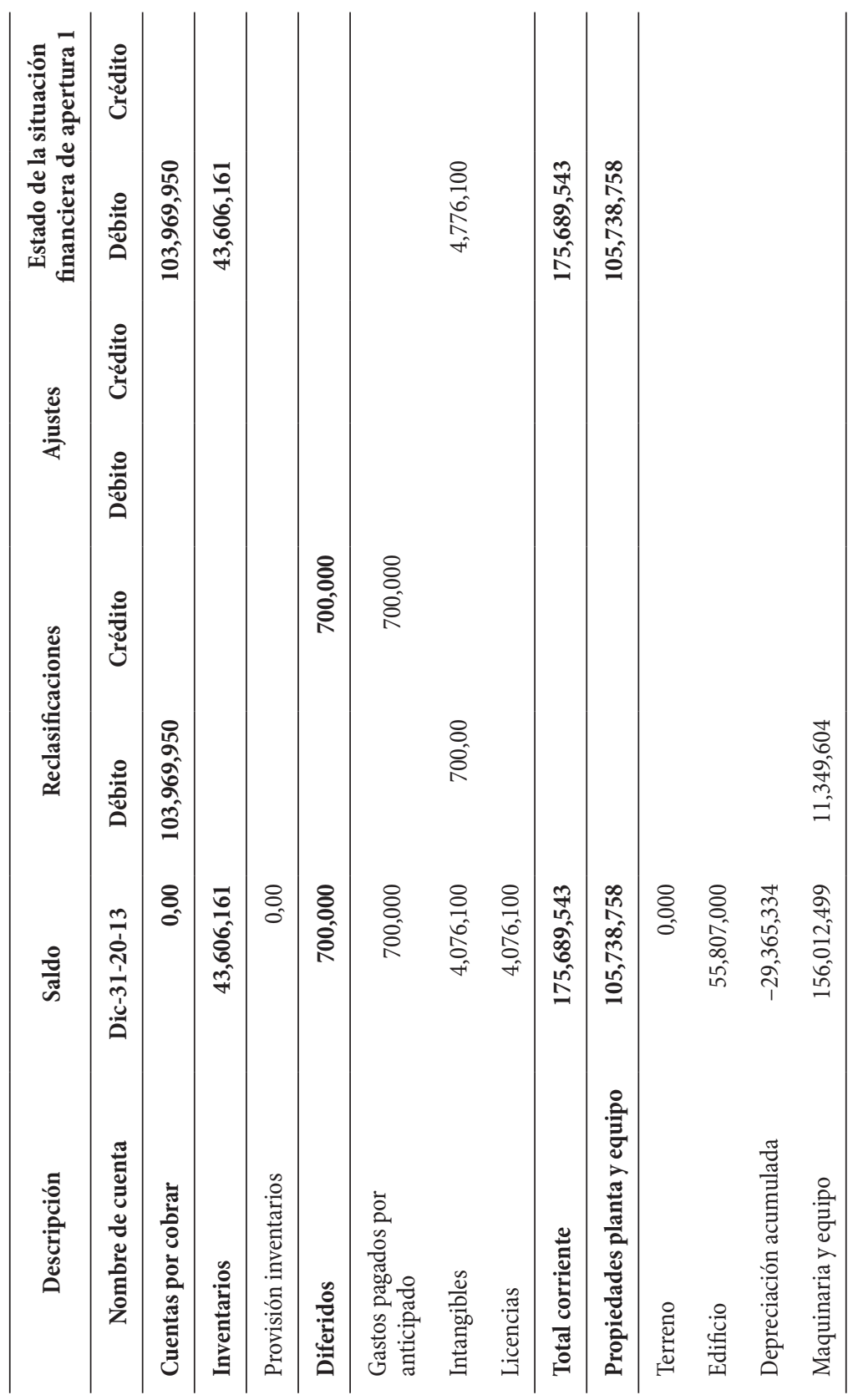




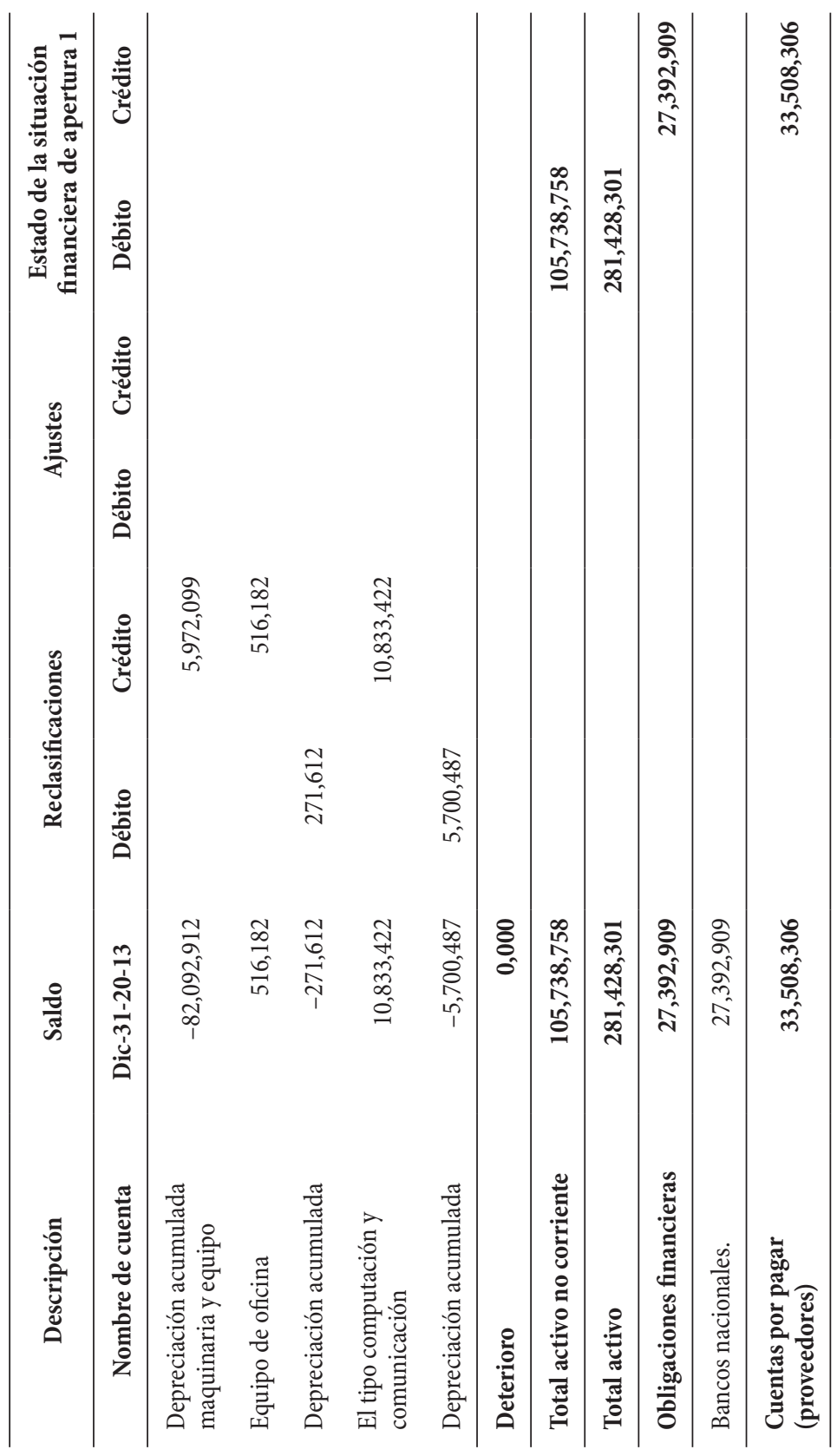




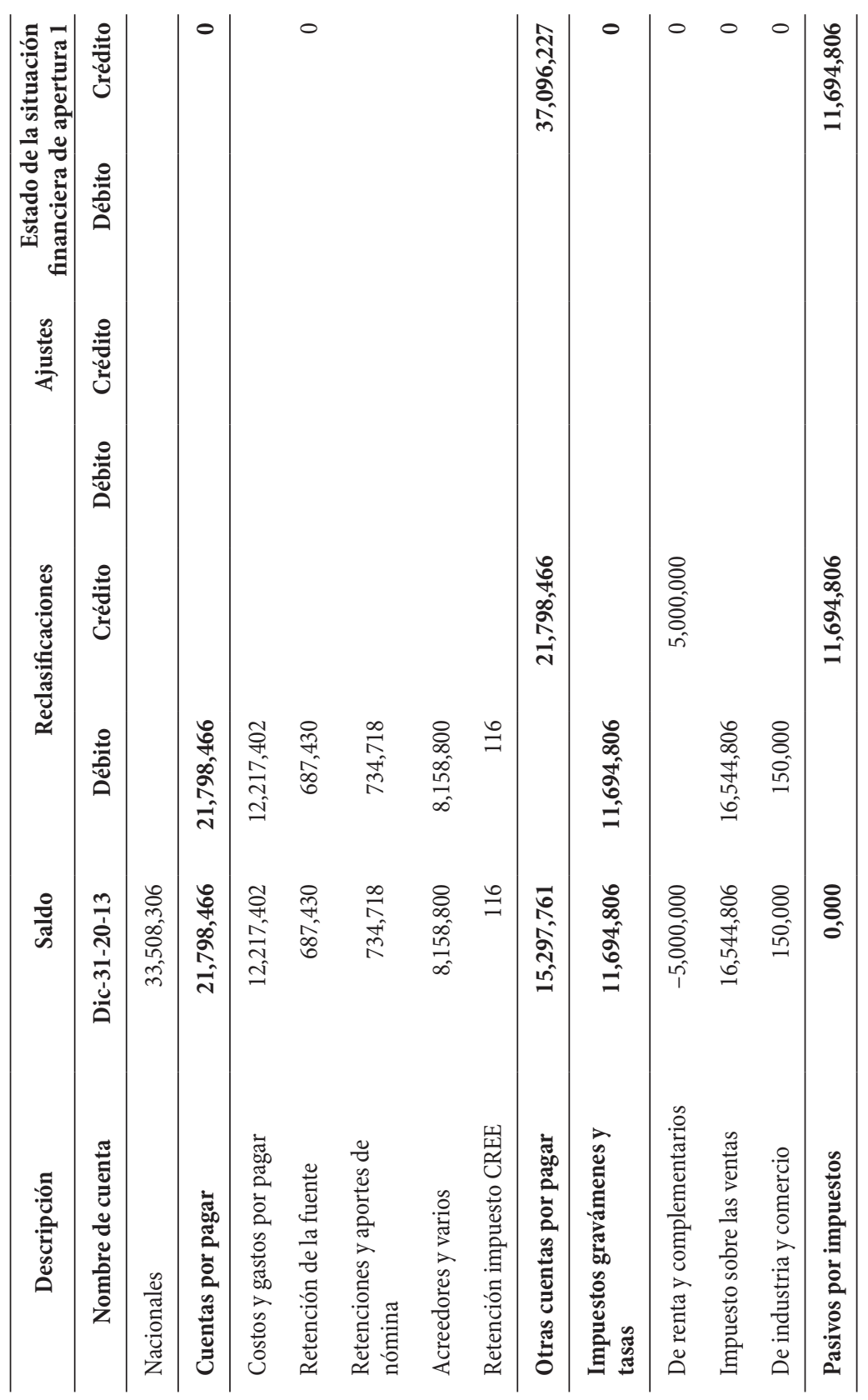




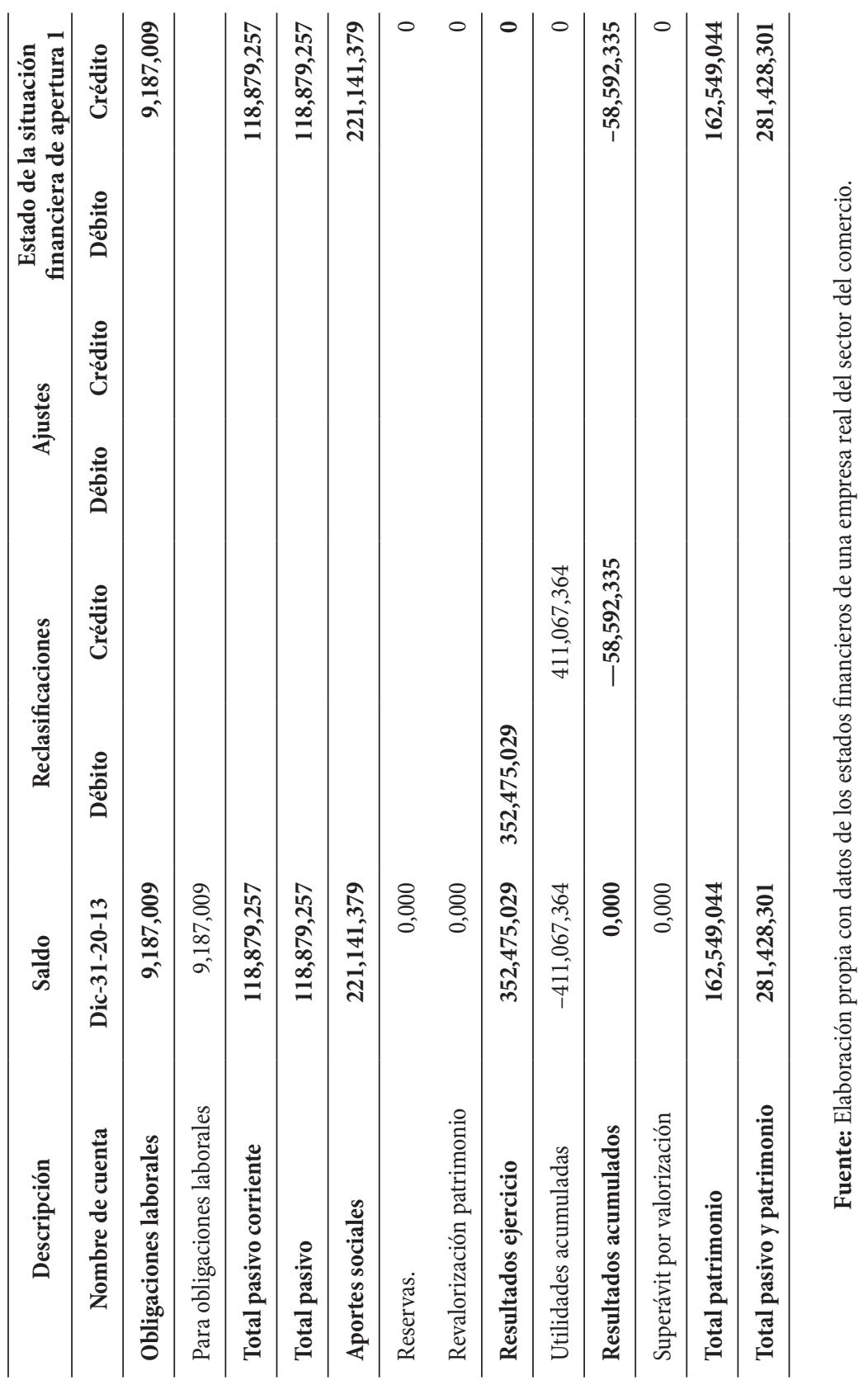




\section{Disponible}

En el nuevo marco regulatorio, contenido en el Decreto 2706 de 2012, uno de los parámetros más importantes se refiere a la revelación plena de la información, por ello, partidas claves como el disponible se deben revelar en los estados financieros o en las notas como efectivo y equivalentes a este, por tal razón se deberá realizar la siguiente reclasificación (ver tabla 5).

Tabla 5. Reclasificaciones en el disponible

\begin{tabular}{|c|c|c|c|}
\hline Denominación & Parcial & Débito & Crédito \\
\hline Disponible & & & $23,337,331$ \\
\hline Caja & 400,000 & & \\
\hline Bancos & $21,863,235$ & & \\
\hline Cuentas de ahorro & $1,074,096$ & & \\
\hline Efectivo y equivalente al EF & & $23,337,331$ & \\
\hline Caja & 400,000 & & \\
\hline Bancos & $21,863,235$ & & \\
\hline Cuentas de ahorro & $1,074,096$ & & \\
\hline
\end{tabular}

Fuente: Elaboración propia con datos de los estados financieros de una empresa real del sector del comercio.

\section{Deudores}

En términos del registro de deudores, la cuenta existente en el decreto 2650, será reemplazada según la normatividad internacional por la denominación Cuentas por cobrar, la cual comprende cuentas con deudores comerciales originadas en el desarrollo de las operaciones, el ejercicio de reclasificación se muestra en la tabla 6. 
Tabla 6. Reclasificación a realizar en la cuenta de deudores

\begin{tabular}{lcc}
\hline \multicolumn{1}{c}{ Denominación } & Débito & Crédito \\
\hline Cuentas por cobrar & $70,838,676$ & \\
\hline Clientes & $57,281,777$ \\
Cuentas por cobrar & $6,441,833$ \\
Deudores varios & $7,115,066$ \\
\hline & & \\
\hline Otras cuentas por cobrar & $\mathbf{3 3 , 5 4 7 , 6 2 2}$ & \\
\hline Anticipos y avances & & $3,817,619$ \\
Anticipo de impuestos & & \\
\hline & & \\
\hline Cuentas por cobrar deterioro & & \\
\hline Provisiones & $416,730,003$ \\
\hline
\end{tabular}

Fuente: Elaboración propia con datos de los estados financieros de una empresa real del sector del comercio.

\section{Inventarios}

Según la normatividad internacional, los inventarios deben ser reconocidos al valor del costo de adquisición, debido a que el tratamiento vigente en Colombia es similar, las partidas de inventarios no son objeto de ajustes ni bajo la contabilidad simplificada.

\section{Propiedad Planta y Equipo}

El nuevo marco normativo sugiere la agrupación en una sola cuenta denominada Propiedad, Planta y Equipo, con excepción de los terrenos y las edificaciones, esto implica un ajuste como el señalado en la tabla 7. 
Tabla 7. Reclasificación a realizar en la cuenta de Maquinaria y Equipo

\begin{tabular}{|c|c|c|c|}
\hline Denominación & Parcial & Débito & Crédito \\
\hline Maquinaria y equipo & & $167,362,103$ & \\
\hline Maquinaria y equipo & & & $156,012,499$ \\
\hline Equipo de oficina & & & 516,182 \\
\hline Equipo de computación y oficina & & & $10,833,422$ \\
\hline $\begin{array}{l}\text { Depreciación acumulada } \\
\text { Maquinaria y equipo }\end{array}$ & & & $117,430,345$ \\
\hline Depreciación acumulada & & $117,430,345$ & \\
\hline
\end{tabular}

Fuente: Elaboración propia a partir de Estados Financieros empresa real del sector del comercio.

\section{Obligaciones financieras, proveedores, cuentas por pagar y otros pasivos}

Según la normativa internacional, todos los obligaciones que la empresa posea con terceros diferentes a impuestos y obligaciones laborales, será reclasificadas bajo la denominación cuentas por pagar. El ajuste sugerido se presenta en la tabla 8 .

\section{Impuestos, gravámenes y tasas}

Al igual que los otros pasivos, los impuestos deben ser reclasificados en la cuenta pasivo por impuestos, tal como se aprecia en la tabla 9. 
220 ACTivos | Daniel Darío Daza Delgado, David Esteban Altamar Romero

Tabla 8. Reclasificación a realizar en la cuenta Cuentas por pagar

\begin{tabular}{|c|c|c|c|}
\hline Denominación & Parcial & Débito & Crédito \\
\hline Cuentas por pagar & & & $97,997,442$ \\
\hline Obligaciones financieras & & $27,392,909$ & \\
\hline Proveedores & & $33,508,306$ & \\
\hline Nacionales & $33,508,306$ & & \\
\hline Cuentas por pagar & & $21,798,466$ & \\
\hline Costos y gastos por pagar & $12,217,402$ & $12,217,402$ & \\
\hline Retención de la fuente & 687,430 & 687,430 & \\
\hline Retenciones y aportes de nómina & 734,718 & 734,718 & \\
\hline Acreedores y varios & $8,158,800$ & $8,158,800$ & \\
\hline Retención impuesto CREE & 116 & 116 & \\
\hline Otros pasivos & & $15,297,761$ & \\
\hline Anticipos y avances recibidos & $15,297,761$ & & \\
\hline
\end{tabular}

Fuente: Elaboración propia con datos de los estados financieros de una empresa real del sector del comercio.

Tabla 9. Reclasificación a realizar en la cuenta Impuestos, gravámenes y tasas

\begin{tabular}{llll}
\multicolumn{1}{c}{ Denominación } & Parcial & Débito & Crédito \\
\hline Pasivos por impuestos & & $\mathbf{1 1 , 6 9 4 , 8 0 6}$ \\
\hline Impuestos, gravámenes y tasas & & $11,694,806$ & \\
De renta y complementarios & $-5,000,000$ & \\
\hline Impuestos sobre las ventas & $\mathbf{1 6 , 5 4 4 , 8 0 6}$ & \\
\hline De Industria y comercio & 150,000 & \\
\hline
\end{tabular}

Fuente: Elaboración propia con datos de los estados financieros de una empresa real del sector del comercio. 


\section{Pasivos estimados}

La cuenta que se tiene de pasivos estimados corresponde a obligaciones laborales, y en virtud de la norma internacional esta debe ser reclasificada a la cuenta de obligaciones laborales de la siguiente manera (ver tabla 10).

Tabla 10. Reclasificación a realizar en la cuenta Obligaciones laborales

\begin{tabular}{lccc}
\hline \multicolumn{1}{c}{ Denominación } & Parcial & Débito & Crédito \\
\hline Obligaciones laborales & & & $7,898,448$ \\
\hline Pasivos estimados & & $7,898,448$ & \\
\hline Para obligaciones laborales & $7,898,448$ & & \\
\hline
\end{tabular}

Fuente: Elaboración propia con datos de los estados financieros de una empresa real del sector del comercio.

\section{Resultados del ejercicio}

Según la normativa internacional las utilidades acumuladas deben ser reclasificadas a resultados del ejercicio (ver tabla 11).

Tabla 11. Reclasificación a realizar en la cuenta Resultados de ejercicios anteriores

\begin{tabular}{lccc}
\hline \multicolumn{1}{c}{ Denominación } & Parcial & Débito & Crédito \\
\hline Resultados acumulados & & & $-411,067,364$ \\
\hline Resultados de ejercicio ante & & $-411,067,364$ & \\
\hline Para obligaciones laborales & $-411,067,364$ & & \\
\hline
\end{tabular}

Fuente: Elaboración propia con datos de los estados financieros de una empresa real del sector del comercio. 
La adopción por primera vez de normas en formato NIIF trae para las microempresas colombianas ajustes y reclasificaciones contables que implican una variación en la presentación de la información financiera, en primer lugar porque hay una reducción de los grupos contables, así como del total de las notas a los estados financieros a revelar, adicionalmente se presenta una nueva asignación y evaluación de activos y pasivos, con respecto a su medición, identificación y reorganización.

El impacto económico que representa la adopción para la empresa seleccionada en este estudio no es significativo en cuanto al incremento o disminución de sus activos pasivos y patrimonio, debido a que en realidad no presentaba revalorizaciones del patrimonio, ni valorización de activos fijos con corte a 31 de diciembre de 2013.

Teniendo en cuenta que esta es una microempresa promedio, con una planta de cinco empleados, dedicada a la comercialización de artículos metálicos para la construcción, con 20 años de funcionamiento en el mercado, que presenta problemas financieros; se puede concluir que la adopción del modelo de contabilidad simplificada no tendrá efectos concretos sobre su situación financiera. Lo que se espera que dicha aplicación si evidencie sea la falta de administración y control de sus operaciones. Este punto se analiza a continuación:

Al ser una empresa comercial de productos al detal, no debería presentar una cuenta por cobrar tan elevada, ni tampoco una cuenta por pagar a proveedores y entidades financieras con montos tan altos. Esto puesto que podría crear expectativas negativas en sus financiadores y con ello perder acceso a crédito y descuentos.

Este ejercicio permite visibilizar una preocupación respecto a los impactos que deberán enfrentar microempresas que sí deban realizar ajustes y eliminaciones con importancia relativa, como valorizaciones de activo, cargos diferidos y revalorizaciones del patrimonio, ya que estas partidas afectan directamente el valor patrimonial también pueden afectar 
la confianza del inversionista o la visión de solvencia y crecimiento por parte de los propietarios generando descontento por la pérdida del valor accionario.

Referente a las valorizaciones el problema consiste en la disminución del valor del activo y el patrimonio, ya que no se reconocerán como un ítem aparte, sino que mediante estudios y avalúos se modificara el valor del activo directamente para obtener un valor en libros razonable y enfocado a la realidad económica de la entidad, hecho que podría no ser contraproducente con respecto al resultado de la microempresa, puesto que si el nuevo avaluó arroja un valor aproximado al que antes se tenía, este hará parte directa del valor en libros, de igual forma ocurre para los avalúos de inversiones.

Con respecto a los diferidos, la norma internacional no permite realizar cargos futuros respecto a partidas que no se consideren activo, por ende, los cargos diferidos se deben reconocer directamente contra el resultado del ejercicio, procedimiento que podría acarrear impactos negativos en cuanto a la rentabilidad inicial del negocio. En Colombia se acostumbraba dividir el valor del gasto preoperativo, en varios meses o inclusive en años futuros, con el fin de que no representara un impacto significativo en el resultado del mes inicial; bajo normatividad internacional este tratamiento no se podrá utilizar. Por ende, una empresa tipo iniciará operaciones con una perdida, lo que le impedirá hacerse atractiva ante una inminente posibilidad de inversión.

Finalmente, la revalorización del patrimonio es consecuencia de los ajustes por inflación que se venían realizando en Colombia y que fueron derogados; sin embargo, estas partidas perduraban en los Estados Financieros. Bajo la nueva normatividad se les debe eliminar y su impacto directo se realizara contra los resultados del ejercicio, así que entre más revalorización tenga cada microempresa, así mismo se verá afectada su situación financiera. 


\section{Principales inconvenientes de una microempresa del sector comercial colombiano a la hora de realizar la adopción contable por primera vez}

El proceso de convergencia a estándares internacionales significa uno de los cambios más representativos de la contabilidad en Colombia en los últimos años; la práctica contable representa uno de los pilares fundamentales en los procesos de internacionalización de un país, de una economía, de un mercado, de una sociedad.

Pese a las ventajas que puede traer consigo dicho proceso, no se debe olvidar el impacto que puede traer consigo el cambio a un modelo contable empleado por más de 20 años, los posibles efectos negativos que acarrearía este cambio de normatividad y la puesta en marcha de este proceso dentro de los empresas, teniendo en cuenta lo que significa un cambio en la forma de pensar de los profesionales de la ciencia contable y de los empresarios como tal.

Si bien se trata de un cambio del ámbito contable en el país, es imposible separarlo del otro grupo de factores que interviene en una economía. En este punto surgen inconvenientes con el proceso de convergencia: el cambio de pensamiento será uno de los puntos más importantes a tratar, resultará más difícil lograr este cambio en las microempresas, si se toma como punto de partida que un porcentaje elevado de estas no implementa contabilidad. Al tratarse de unidades económicas con poco o ningún conocimiento de la utilización de la contabilidad, resultará en primera instancia un reto dar a conocer la importancia del uso de la contabilidad dentro de estas empresas e iniciar su aplicabilidad. 


\section{Comparación entre contabilidad simplificada para microempresas y NIIF para Pymes}

Teniendo en cuenta los elementos señalados, es importante puntualizar algunos de los cambios entre los distintos sistemas de contabilidad que de ahora en adelante se deben aplicar bajo el ordenamiento de la Ley 1314. Las diferencias entre los modelos de NIIF plenas y NIIF para Pymes así como el modelo de contabilidad simplificada son sustanciales, pero resulta más interesante analizarlo para los dos últimos modelos en este sentido las principales diferencias son:

- Bajo el estándar NIIF para Pymes las normas cuentan con 35 secciones específicas, cada una dirigida a un tema.

- El estándar de contabilidad simplificada solo cuenta con 15 capítulos que abarcan lo que a consideración del CTCP es necesario.

- En contabilidad simplificada no existe normatividad referente a consolidación de información financiera, se eliminan algunas reglamentaciones por considerarse complejas para este tipo de empresas.

- Las microempresas solo emitirán tres de los Estados Financieros Básicos: Balance General, Estado de Resultados y las notas, pero de manera simplificada. Es importante recordar que las notas a los estados financieros hacen parte de estos como un todo indivisible, de acuerdo al artículo 36 de la Ley 22 de 1995.

- Es necesario comentar que la contabilidad simplificada comparte las mismas características cualitativas requeridas de la información para Pymes; el lenguaje utilizado fue sintetizado y simplificado para facilitar su interpretación y aplicabilidad.

- Otro tema de importancia significativa corresponde a los cambios en el principio de esencia sobre forma, ya que no es usual dejar al libre albedrío de cada profesional algunas de las decisiones puntuales 
según las necesidades de la información manejada. Durante años se ha ceñido a unos ítems puntales los cuales se debían que seguir asiduamente, evitando a toda costa la interpretación y manejo particular.

- Los principios para obtener información son iguales para los dos tipos de contabilidades, en ambos sistemas regulatorios, la vida útil, destinada a unos usuarios internos o externos, por ello debe ser clara relevante y sobre todo orientada para la toma de decisiones, por ello se debe evitar a toda costa sesgos en la información.

- La contabilidad se continuara realizando siguiendo el principio de causación, pero es de anotar que internacionalmente esto se conoce como sistema de acumulación o devengo, y esto se utiliza puntualmente para evitar la manipulación de información para obtener suficiente criterio y confianza en la información.

- La base de medición principal es el costo histórico por la facilidad de aplicabilidad, no se habla de prohibición de aplicación de otros métodos en la contabilidad simplificada, pero es de aclarar que si se opta por otro puede tener efectos de carácter económico.

\section{Conclusiones}

- Las microempresas representan la mayor fuerza económica y la principal fuente de empleo del país, y son el tipo de empresas que poseen la mayor cantidad de trabajo informal. Con las herramientas y métodos adecuados podrían mejorar su aporte económico y su capacidad de crear empleos de calidad.

- El modelo de contabilidad simplificada es resultado de una simplificación realizada a las NIIF para Pymes, con la cual comparte principios, cualidades y diferentes criterios para la revelación de la información. Sin embargo, no es posible considerar que las normas 
de contabilidad simplificada sean $100 \%$ norma internacional, puesto que el Decreto 2706 de 2012 solo es de jurisprudencia nacional y tiene algunos elementos que no son totalmente alineados con el modelo internacional.

- Los factores que inciden en el hecho de que las microempresas hagan una adopción correcta de las NIIF simplificadas, están ubicados fundamentalmente en el frente financiero, inicialmente porque el obtenido en la operación comercial y productiva es invertido por los mismos dueños en funciones de sobrevivencia, adicionalmente porque las unidades microempresariales no tienen capacidad económica para la realización de avalúos, el tema de contratación de personal capacitado para la convergencia, las eliminaciones y ajustes de la contabilidad que pueden ser desfavorables para la inversión.

- El gobierno colombiano tiene una tarea difícil para lograr que todas las microempresas lleven contabilidad bajo los lineamientos adecuados para poder realizar la convergencia hacia estándares internacionales, y debe seguir proponiendo soluciones e impulsando campañas para que el empleo informal deje de serlo y haga parte del número de empresas bien constituidas, procurar que puedan tener continuidad en el mercado y poder atraer inversión para su crecimiento.

- La falta de implementación de la contabilidad y su utilización incorrecta en las microempresas colombianas, genera un conflicto al momento de converger hacia estándares internacionales, debido a que los parámetros que estas requieren como mínimo, no serán fácilmente alcanzados.

- La implementación del Decreto 2706 de 2012 no es un proceso complejo. Cabe anotar que las microempresas que cuentan con cierto tipo de activos, pueden tener un impacto mayor, y también que se debe incentivar al microempresario a la utilización de prácticas contables, es verdaderamente importante demostrarle la utilidad 
que esta puede tener a la hora de la toma de decisiones y sobretodo como carta de presentación de prosperidad de las empresas.

- Es indudable que la preocupación por el desarrollo de las microempresas se ha convertido recientemente en una importante política de Estado, de hecho la reglamentación de su contabilidad también busca formalizarlas. Aunque es importante señalar que estos esfuerzos no son suficientes, para algunas de estas entidades la transición o aplicación en su contabilidad no tendrá un impacto relevante, pero puede existir casos donde llegué a ser significativo, una solución estaría en crear de una institución especializada en la microempresa que se concentre en la colaboración y orientación respecto a este tema específico.

- La normatividad emitida hasta el momento no contiene la información necesaria para desarrollar la convergencia y especialmente la adopción por primera vez a estándares internacionales de contabilidad, por eso es indispensable tener en cuenta la reglamentación que otros entes de control emiten. 


\section{Referencias bibliográficas}

Banco de la República. (2011). Boletín de indicadores económicos. Recuperado de http://www.banrep.gov.co/sites/default/files/paginas/bie.pdf

Comisión Europea. (2006). La nueva definición de Pyme. Guía del usuario u ejemplo de declaración. DG, Empresa e industria. Bruselas.

Giraldo, B. H. (2007). Estadistica de la Microempresa en Colombia, Analisis Comparativo 1990-2005. Bogotá.

Comision Europea. (2006). La nueva definicion de pyme. En La nueva definicion de pyme (pág. 12). Publicaciones de Empresa e Industria.

Departamento Nacional de Planeacion. (13 de Agosto de 2007). Conpes 3484 de Agosto 13 de 2007. Política nacional para la trasnformación productiva y la promoción de las micro, pequeñas medianas empresas: Un esfuerzo públicoprivado. Bogotá, Colombia.

Decreto 2706. (27 de Diciembre de 2012). Bogotá, Colombia.

Ramírez, M. C. (4 de Octubre de 2013). Culpables, jueces y verdugos en la caída de la primera comisionista de bolsa. La Republica.

Codigo Comercio. (1971). Libro 1, Cap 2, Tit 2, Art 25. Bogotá.

Ley 1450. (26 de Junio de 2011). Diario Oficial, pág. 8.

Ley 590. (2000). Bogotá.

Montoya, C. C. (5 de Abril de 2011). El racionamiento der crédito a las microempresas en Colombia. Un estudio de los tipos de racionamiento, Bogotá, Colombia.

DANE. (26 de Junio de 2013). Boletín de Prensa. Ecuesta de Microestablecimientos. Bogotá, Colombia.

Banco de la Republica. (27 de Enero de 2014). Recuperado el 1 de Febrero de 2011, de http://www.banrep.gov.co/sites/default/files/paginas/bie.pdf

Marco de referencias NIFF Grupo 1. (s.f.). Adopcion por prmera vez de las Normas Internacionales de Informacion Finanaciera.

Decreto 2784. (28 de Diciembre de 2012). Marco Técnico Normativo para los preparadores de información financiera que conforma el Grupo 1. Bogotá, Colombia.

Quintero, H. G. (2012). Contextualización Microempresas en Colombia. Guia de entendimiento del proecto de norma de información financiera para las Microempresas. 
Fundación IFRS. (9 de Julio de 2009). Material de formación para las Pmes Modulo 35. Comparación NIIF para Pmes con NIIF para Mipymes Grupo 2.

Torres, L. L. (2007). Adopción de normas Internacionales por primera vez. Bogotá, Colombia.

Barrientos, M. (2012). Nomras Internacionales de información financiera NIIFIFRS ejemplos, ejercicios y casos prácticos comentados.

El tiempo. (31 de Mayo de 1991). Recuperado el 28 de Abril de 2013, de http:// www.eltiempo.com/archivo/documento/MAM-93252

Manay, G. M. (31 de Enero de 2012). Las Micro, Pequeñas y Medianas empresas y su participaciçon en el desarrollo social crecimiento económico de América Latina.

Super Sociedades. (14 de Marzo de 2012). Recuperado el 29 de Agosto de 2013, de http://www.supersociedades.gov.co/ss/drvispa.dll?mival=muestra\&id _pag $=32158 \& \mathrm{t}=1$

Camara Comercio Medellín. (2011). Recuperado el 28 de Agosto de 2013, de http://www.camaramedellin.com.co/site/Portals/0/Documentos/Memorias /2011/6Normas_internacionales_Contabilidad.pdf

Superintendencia de Sociedades. (14 de Marzo de 2013). www.supersociedaes.gov. co. Recuperado el 29 de Agosto de 2013, de http://www.supersociedades.gov. co/ss/drvisapo.dll?MIval=muestra\&id_pag $=32158 \& \mathrm{t}=1$

Diario Oficial No 42.156. (20 de Diciembre de 1995). Ley 222 . Bogota, Colombia, Colombia: Imprenta Nacional.

Diario Oficial No 47.409. (13 de Julio de 2009). Ley 1314. Bogotá, Colombia: Imprenta Nacional.

Diario Oficial No 44.078. (12 de Julio de 2000). Ley 590. Bogotá, Colombia, Colombia: Imprenta Nacional.

Diario Oficial No 48.102. (16 de Junio de 2011). Ley 1450. Bogotá, Colombia, Colombia: Imprenta Nacional.

Ministerio de Comercio, Industria Turismo. (27 de Diciembre de 2012). Deloitte. com.co. Recuperado el 18 de Diciembre de 2013, de http://webserver2.deloitte. com.co/Doc\%20IFRS/Decreto\%20Numero\%202706\%20de\%202012.pdf

Departamento Administrativo Nacional de Estadistica [DANE]. (26 de Junio de 2013). Boletìn de Prensa. Encuesta de Microestablecimientos Panel de Firmas 2012 . Bogotá, Colombia, Colombia: www.dane.gov.co. 
Banco de la Republica. (27 de Enero de 2011). Boletin de Indicadores Economicos. Recuperado el 1 de Febrero de 2014, de http://www.banrep.gov.co/sites/default/ files/paginas/bie.pdf

Diario Oficial No 33.339. (27 de Marzo de 1971). Codigo de Comercio (Decreto 410). Bogotá, Colombia: Imprenta Nacional.

Comision Europea. (2006). La Nueva definicion de pyme. En la Nueva deficion de Pyme, Pag. 12.

Departamento Nacional de Planeación [DNP]. (13 de Agosto de 2007). CONPES 3484. Política nacional para la transformacion productiva y la promocion de las micro, pequeñas medianas empresas: Un esfuerzo publico-privado. Bogotá, Colombia.

Giraldo, B. H. (Abril de 2007). Estadistica de la Microempresa en Colombia Analisis Comparativo 1990-2005. Bogotá, Colombia.

Montoya, C. C. (2011). El racionamiento de credito a las microempresas de Colombia. Un estudio de los tipos de racionamiento. Coyuntura Economica, Vol. XLI, No 1, Pags. 225-255.

Ramirez, M. C. (4 de Octubre de 2013). Culpables, jueces y verdugos en la caída de la primera comisionista de bolsa. La Republica, págs. http://www.larepublica. co/finanzas/culpables-jueces-y-verdugos-en-la-ca\%C3\%ADda-de-la-primeracomisionista-de-bolsa_67161.

Departamento Administrativo Nacionla de Estadistica [DANE]. (22 de Mayo de 2005). Censo General. Bogotá, Colombia, Colombia: www.dane.gov.co.

Diario Oficial No 45.628. (2 de Agosto de 2004). Ley 905. Bogotá, Colombia, Colombia: Imprenta Nacional.

Gonzáles, I. (2003). Contabilidad internacional. México: Mcgraw-Hill.

Superintendencia de sociedades. (2012). Comportamiento de los grupos empresariales del sector real de la economía. Bogotá: Superintendencia de sociedades.

Pérez, S. (7 de Diciembre de 2012). Empresas del sector real impulsaron las emisiones de renta fija en el mercado. Diario la república.

IFRS. (27 de 05 de 2014). Ifrs. Obtenido de eifrs.iasb.org: http://eifrs.iasb.org/eifrs/ bnstandards/es/2012/Framework.pdf

Hernández R, M. (2000). La perspectiva sociológica de los actores empresariales. Fondo de Cultura Económica. 